Sharif University of Technology
Scientia Iranica
Transactions A: Civil Engineering
SCIENTIA
IRAN I CA

\title{
Uncertainty quantification in seismic collapse assessment of the Iranian code-conforming RC buildings
}

\author{
S.A. Hoseini ${ }^{a}$, M. Ghaemian ${ }^{a, *}$, and M.A. Hariri-Ardebili ${ }^{b, c}$ \\ a. Department of Civil Engineering, Sharif University of Technology, Tehran, Iran. \\ b. Department of Civil Engineering, University of Colorado, Boulder, USA. \\ c. X-Elastica LLC, Boulder, Colorado, USA.
}

Received 1 March 2018; received in revised form 5 July 2018; accepted 22 October 2018

\section{KEYWORDS}

Collapse;

Incremental dynamic

analysis;

Fragility curve;

Confidence level;

Uncertainty.

\begin{abstract}
Structural collapse is the main concern for the existing structures which are built in the seismic-prone regions. Therefore, the primary goal of the seismic provisions in building codes is to prevent the global collapse. Iran is located in the Alpine-Himalayan belt, and has experienced some of the most destructive earthquakes in the past century. To evaluate the extent to which the Iranian building code provisions meet the abovementioned objective, the authors conducted a detailed assessment of collapse risk on a set of moderate moment resisting Reinforced Concrete (RC) buildings. While many features might affect the seismic performance of the RC structures, this study considers $P-\Delta$ effects, deterioration in strength and stiffness, and cyclic deterioration in structural components. Structural assessment was performed using OpenSees platform and the multiple-record Incremental Dynamic Analysis (IDA). Results were obtained in terms of IDA capacity curves and collapse fragility functions at different seismic hazard levels. Results showed that probability of instability increased with height of the buildings. Moreover, the collapse confidence level was evaluated considering the available uncertainties. Assuming a minimum confidence level of $90 \%$ for the buildings, the Collapse Prevention (CP) Limit State (LS) under the 2\%/50 yr hazard level was not satisfied for the 9- and 12-story frames, and they needed to be re-designed.
\end{abstract}

(C) 2020 Sharif University of Technology. All rights reserved.

\section{Introduction}

In earthquake engineering, "structural collapse" refers to the inability of a structural system, or part of it, to maintain the load-carrying capacity under seismic excitation. Collapse can be in the local or global levels. The former may occur, for example, if a vertical loadcarrying component fails in compression, or if shear transfer is lost between the horizontal and vertical components (i.e., shear failure between flat-slab and

*. Corresponding author.

E-mail address: ghaemian@sharif.edu (M. Ghaemian) a column). One the other hand, global collapse may occur in several ways: the spread of an initial local failure from element to element may result in cascading or progressive collapse. Incremental collapse occurs if the displacement of an individual story is very large (and the second-order $P-\Delta$ effects fully offset the firstorder story shear resistance). In either case, replication of the collapse necessitates modeling of deterioration characteristics of the structural components subjected to cyclic loading (including the $P-\Delta$ effects).

During the past earthquakes, several collapses in modern building structures have been reported even though these structures were built in accordance with modern seismic design codes and construction standards. A recent example is the global collapse of 
the 15-story Reinforced Concrete (RC) residential AltoRio building during the 2010 Maule, Chile earthquake, which had been constructed following the Chilean building codes [1]. Such an observation raises some important questions regarding the capability of the current seismic provisions to provide safety against structural collapse under extreme seismic forces [2]. Therefore, it is crucial to understand the causes and effects of the structural collapse in order to develop the key documents such as national building codes, regional emergency response plans, and risk management strategies.

In Subsection 1.1, a group of published research articles in seismic collapse assessment of the structures is reviewed. The emphasis will be on the papers related to:

1. Collapse in RC structures under dynamic excitation;

2. Advance techniques in uncertainty quantification of the framed structures.

Next, the objectives of the present paper will be discussed in Subsection 1.2.

\subsection{Literature review}

1.1.1. Modeling, analysis, and uncertainties

In general, the research topics in the field of concrete structures can be classified as:

- Experimental studies in which a full or scaled down model of the RC frames is tested in the lab. 2D and 3D models are both used for the experiments based on the shake table test, centrifuge, and actuators. Results are usually used for validation of the finite element models;

- Numerical studies which comprise the majority of the existing literature on RC frames. There are two major goals in this part:

- Developing a constitutive model for the nonlinear response of the concrete, its interaction with reinforcement, and damage simulation. This is an active research field in both micro and macro modeling of the material, structural components and equivalent simplified models. This branch mainly quantifies the epistemic uncertainty in material and modeling;

- Investigation into the dynamic response of the $\mathrm{RC}$ frames considering different characteristics of input excitation. Record-To-Record (RTR) variability, mainshock-aftershock effect, nearversus far-field ground motions, directivity, etc. are some of the typical features in this branch. In general, the aim of this group of studies is to quantify the aleatory uncertainty in the demand parameters.
- Risk studies in which the raw data from structural and damage analyses are used for the subsequent loss analysis. Finally, these data help to improve the reliability of the structural systems and risk-based decision making.

This subsection is dedicated to the review of some of the recently published and highly cited papers regarding the modeling, analysis, and uncertainty quantification of the RC framed structures. Note that although many other papers could be listed in our short literature review, we kept the list concise.

Kunnath et al. [3] developed an analytical modeling scheme to evaluate the damageability of $\mathrm{RC}$ buildings experiencing inelastic behavior under seismic excitation. The numerical model was capable of simulating the ductile moment-resisting frames with shear wall and out-of-plane transverse behavior. The structural model was a combination of concentrated plasticity at the member ends and distributed flexibility for the element. Baker and Allin Cornell [4] considered the spectral shape in collapse assessment of structures. Lumped plasticity was assumed for the beam-column elements and implemented in the OpenSees software [5]. Incremental Dynamic Analysis (IDA) was then performed to simulate the sideways collapse of the frames.

Goulet et al. [6] evaluated the seismic performance of the RC frames employing the Performance-Based Earthquake Engineering (PBEE) framework. Performance was quantified in terms of collapse safety and economic losses. Structural responses included both the ground motion uncertainties and the structural modeling issues. They reported a collapse probability in the range of $2-7 \%$ for the buildings subjected to excitations, which were scaled to a hazard level equivalent to $2 \% / 50 \mathrm{yr}$.

Structural modeling is an important issue in seismic response of concrete structures. Haselton et al. [7] evaluated the collapse performance of $30 \mathrm{RC}$ special moment frame buildings ranging from 1 to 20 stories including parametric design variations. The buildings were designed according to the American Society of Civil Engineers (ASCE) provisions [8]. Modeling uncertainties were considered in collapse predictions. They found that for 2\%/50 yr hazard level, the conditional collapse probability ranged within 3-20\% with an average value of $11 \%$. The mean annual frequency of collapse ranged from $0.7 \mathrm{e}-4$ to $7.0 \mathrm{e}-4$ collapses per year with an average rate of $3.1 \mathrm{e}-4$. This study suggested that the minimum base shear requirement was an important component in ensuring relatively consistent collapse risks for buildings of varying heights. Neglecting this requirement has made taller buildings more vulnerable to collapse.

Liel et al. [9] carried out probabilistic assessment 
of structural collapse risk through nonlinear time history analysis including the material and modeling uncertainties. Variables such as modeling deformation capacity and post-peak softening response of the components might have a significant influence on the predicted collapse performance [10]. Later, Haselton et al. [11] added the concept of performance-based assessment to enrich the specific design requirements for seismic collapse resistance. Two criteria were considered: 1) the minimum base shear requirement based on ASCE, and 2) the strong-column weakbeam concept based on American Concrete Institute (ACI) [12].

Dolsek [13] proposed the extended version of IDA technique in order to include the effects of epistemic uncertainties on the responses. In this method, they first proposed a set of structural models with different combinations of material uncertainties. Then, they applied the conventional IDA to each structural model. Finally, they integrated all the individual IDA curves in the form of fragility function. They applied this technique to a four-story RC frame. Moreover, Celarec and Dolsek [14] conducted a similar research in which the elastic beam-column elements had inelastic rotational hinges at their ends (lumped plasticity). The tri-linear moment-rotation relationship in the plastic hinges was the only source of nonlinearity. It was found that the seismic performance of the old 3-story buildings was mainly controlled by the ultimate rotation of the plastic hinges in the columns, whereas in the case of the contemporary buildings, the ultimate rotation of the beams was the controlling parameter.

Based on a series of numerical studies of two RC frame structures, Li et al. [15] claimed that the thencurrent tie-force method was inadequate in increasing the progressive collapse resistance (since it did not consider load redistribution in 3D, dynamic effect, and internal force correction). Then, an improved version of tie-force method was proposed and its reliability for the RC frames was verified. In a comprehensive paper, Kam et al. [16] described the observations of damage to RC buildings in the February 22, 2011 Christchurch earthquake. Damage statistics and typical damage patterns were presented for various configurations and lateral resisting systems. They emphasized the fact that some aspects of the seismic design should be improved.

Fragiadakis et al. [17] studied the applicability of nonlinear static procedures to estimating the seismic demands of the typical moment-resisting $\mathrm{RC}$ frames. They compared different nonlinear static procedures and validated them by the nonlinear response history analysis. They quantified the degree to which the nonlinear static methods could characterize the local and global demand parameters. Lu et al. [18] investigated the collapse resistance of two existing $\mathrm{RC}$ high-rise buildings of 18- and 20-story frame-core tube systems. They used the finite element technique with fiber beam element model, multilayer shell model, and elemental deactivation technique to predict the collapse process.

Raghunandan and Liel [19] studied the effect of ground motion on the collapse of $2 \mathrm{D} \mathrm{RC}$ frame structures. The structural models included three bay frames with different heights. They used the OpenSees software and the lumped plasticity beamcolumn elements [20] in conjunction with inelastic joint shear springs. IDA technique was employed to perform numerous nonlinear simulations. Furthermore, Raghunandan et al. [21] quantified the aftershock vulnerability of four modern ductile RC framed buildings in California by conducting IDA on nonlinear analytical models. Collapse and damage fragility curves were subsequently derived. They reported that if the building was extensively damaged in the mainshock, there was a significant reduction in its collapse capacity in the aftershock. In addition, Riahi et al. [22] compared the seismic structural responses of a set of $\mathrm{RC}$ moment resisting frames under excitation of real accelerograms and ground motions that spectrally matched a target spectrum. The matching process was conducted in the time domain and ASCE 7-05 was used as the target spectrum.

Sattar and Liel [23] studied the impact of three collapse indicators (i.e., column-to-beam strength ratio, shear strength ratios in adjacent stories, and flexural-to-shear strength ratio of the column) on the collapse performance of RC moment frames. They also quantified the relation between collapse performance and collapse indicators for varying column and frame characteristics. They reported that for the buildings with flexurally dominated columns, the significance of deficiency was important, while for the shear-critical columns, the location and significance of the deficiency were the covering parameters. Some other researchers focused on the interaction between the infill walls and the concrete frames, e.g., [24,25]. They studied the collapse mechanism of retrofitted frames compared with bare frame. Sustainability of the RC-framed structures was studied in the context of PBEE by Haghpanah et al. [26]. Moreover, Tafakori et al. [27] investigated the dominant collapse mechanism in RC frames accounting for modeling uncertainty and RTR variability based on IDA.

\subsubsection{National and international codes}

One of the final goals of all the research studies is to propose a model and/or criteria to be used by practitioners. There are several studies in which the seismic performance of $\mathrm{RC}$ buildings designed according to the current design codes is investigated. Kueht and Hueste [28] and Kim and Kim [29] studied the seismic performance of an RC building designed 
based on the 2003 International Building Code (IBC). Panagiotakos and Fardis [30] validated the seismic performance of RC buildings based on Eurocode 8. Kotronis et al. [31] developed a simplified approach for $\mathrm{RC}$ walls, which was a combination of the Bernoulli multi-layer beam elements, the concept of damage mechanics, and plasticity. Then, they adopted the model to simulate two RC wall specimens designed based on French code PS92 and Eurocode 8. Sadjadi et al. [32] investigated different aspects of the RC-framed structures designed based on the National Building Code of Canada. Similar researches were reported by Tena-Colunga et al. [33] for the buildings designed according to the Mexico Federal District Code. Moreover, Mehanny and El Howary [34] and El Howary and Mehanny [35] focused on the buildings designed based on the Egyptian seismic code. Finally, Duan and Hueste [36] investigated the seismic performance of a multi-story RC-frame building designed according to the provisions of the current Chinese seismic code, GB50011-2010. Astriana et al. [37] utilized fragility curves in order to compare the seismic performances of moment-resisting frames and frame-wall systems. Results were compared based on the recommended methods in HAZUS-MH MR5 and ATC-40.

The above review of the previous studies shows the lack of a comprehensive study of the seismic performance of RC buildings designed according to the Iranian national regulations. Iran is a seismic-prone country located on the Alpine-Himalayan orogenic belt and has experienced several distributive earthquakes in the past decades. According to Saloor and Salari [38], there have been over 100,000 losses of lives as a results of earthquakes in Iran over the past 35 years. Figure 1 illustrates the level of seismicity in Iran during the

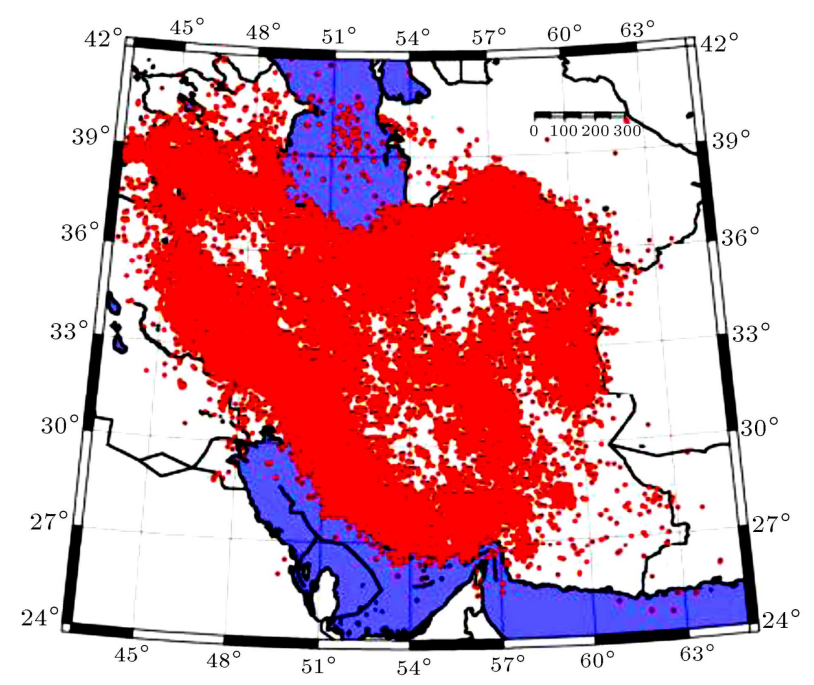

Figure 1. Seismicity of Iran; original data from Iranian Seismological Center for the period of 2006-2015 adopted from [38].
2006-2015 period. Some of the major past earthquakes were: the $1996 M_{w}=6.1$ earthquake in Ardabil, the $2003 \mathrm{M}_{w}=6.6$ earthquake in Bam, the $2012 M_{w}=6.4$ earthquake in Ahar, and the $2017 M_{w}=7.3$ earthquake in Kermanshah. The seismic site effect for the city of Tehran can be found in $[39,40]$.

\subsection{Objectives}

Statistically, most of the concrete buildings in Iran have been designed and built with a moment-resisting frame system. The majority of the past studies examining vulnerability of concrete buildings have been devoted to short buildings with a special moment-resisting frame system or frame-wall system. However, a large number of short- and mid-rise buildings are designed at the level of moderate ductility according to the ninth article of the national building regulations.

Therefore, in this research, the effects of structural height and average ductility capacity level on Collapse Prevention (CP) and Global Instability (GI) performance levels are investigated. To consider the height effect, five types of buildings are designed with the numbers of stories of $3,6,9,12$, and 15 . The major objectives of the study are summarized as follows:

- Utilizing an effective procedure to identify collapse criteria for framed structures in terms of their dynamic instability, i.e., the loss of the ability to sustain the gravity loads;

- Developing a probabilistic approach to collapse assessment based on collapse Limit State (LS) to achieve a reliable probabilistic evaluation of structural collapse;

- Providing fragility functions through systematic treatment of uncertainties in seismic capacity, demand, and structural models for integration into PBEE framework;

- Evaluating decadency of the designed structures for a $2 \% / 50$ yr event in different locations of Tehran.

\section{Case studies}

Five buildings with $3,6,9,12$, and 15 stories were designed according to the Iranian concrete code (aka ABA) and Iranian code of practice for seismic resistant design of buildings (aka Standard 2008), and further controlled based on ACI 318-11 criteria [12]. All the structures were designed as residential buildings. All the 3D modeling and design processes were conducted using ETABS software [41]. Plan view of the buildings with the story height of $3.20 \mathrm{~m}$ is shown in Figure 2 . It is assumed that the buildings are located in an area at a high relative seismic risk with soil Type II. Ductility of the structures is assumed to be moderate, i.e. $R=7$. Dead and live loads are assumed to be 650 and $200 \mathrm{~kg} / \mathrm{m}^{2}$, respectively. Compressive 
strength of the concrete is $240 \mathrm{~kg} / \mathrm{cm}^{2}$ and the main and enclosing reinforcement yield resistances are 4,000 and $3,000 \mathrm{~kg} / \mathrm{cm}^{2}$, respectively. The ceiling system is in the form of joists and a block; the direction of

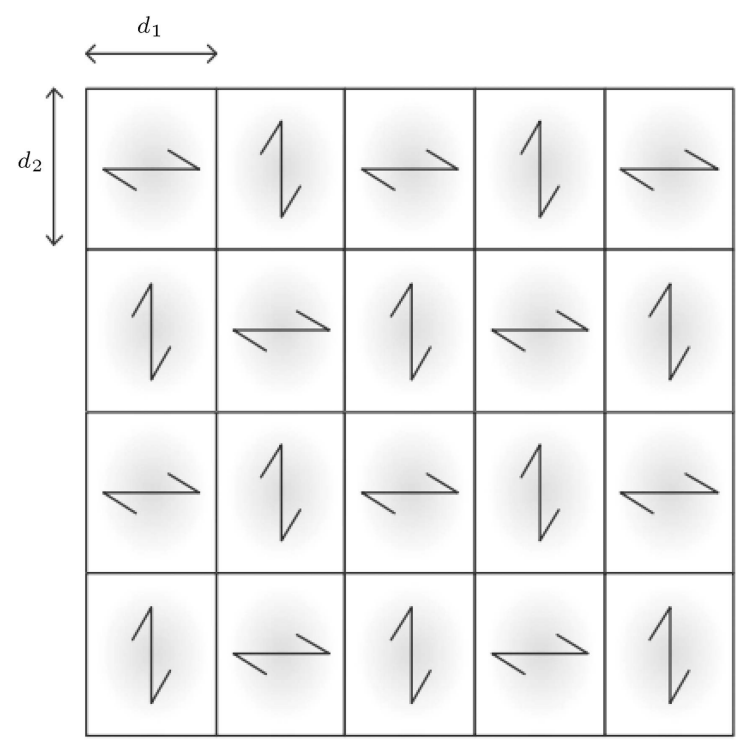

Figure 2. Plan view of the designed buildings; for 3-, 6-, and 9-story frames: $d_{1}=4.0 \mathrm{~m}$ and $d_{2}=5.0 \mathrm{~m}$; for the 12 - and 15-story frames: $d_{1}=5.0 \mathrm{~m}$ and $d_{2}=6.0 \mathrm{~m}$. joists is shown in Figure 2. Moreover, relative interstory drift for the buildings (as a result of linear seismic design) and the allowable drift as per the Iranian code of practice for seismic resistant design of buildings (aka Standard 2008) are shown in Figure 3. As seen, the displacements meet the requirements.

To evaluate the nonlinear behavior of the designed frames, OpenSees software with plastic hinge modeling method is used [5]. In this method, the nonlinear behavior of the elements is defined by plastic hinges and devoted to the element in the middle of the socalled plastic region (which is one of the nonlinearity sources in the element). The model used for the plastic hinge is shown in Figure 4(a).

These relationships are suitable for modeling the elements of the designed buildings. The model used by Haselton et al. [42] for the nonlinear behavior of beam and column elements is the peak-oriented one presented by Ibarra et al. [20]. This hysteresis model is plotted in Figure 4(a). It has the ability to take into account deterioration in stiffness and resistance in different behavioral branches. In Figure 4(b), the observed hysteresis behavior is compared with the results of a laboratory test carried out at the University of Tehran [43]. As seen, there is a good consistency between the numerical and experimental models.

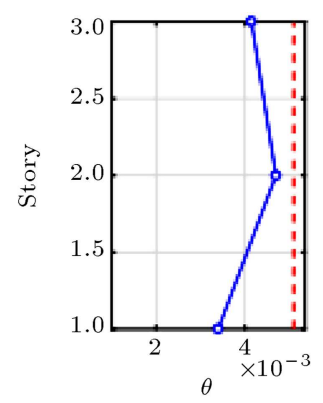

(a) 3

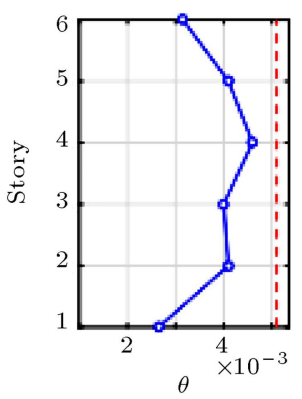

(b) 6

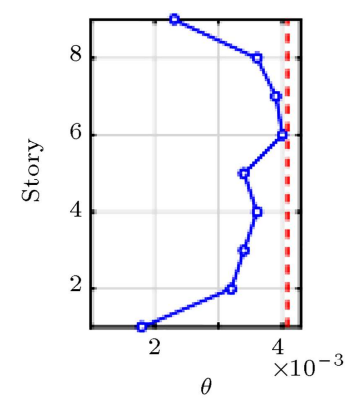

(c) 9

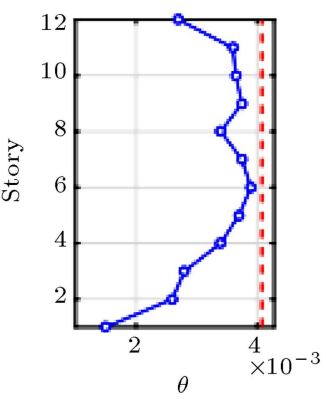

(d) 12

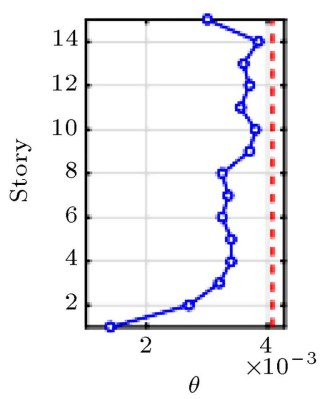

(e) 15

Figure 3. Relative inter-story drift and the allowable values according to the Iranian code of practice for seismic resistant design of buildings (aka Standard 2008).

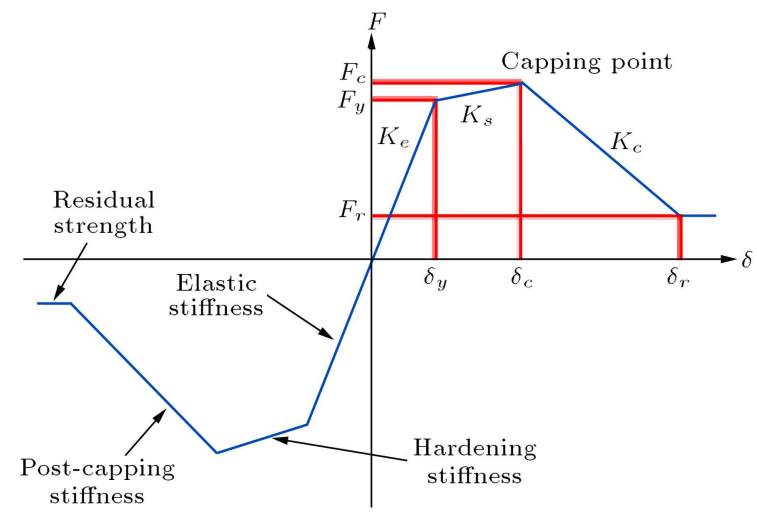

(a) Hysteresis behavior based on [36]

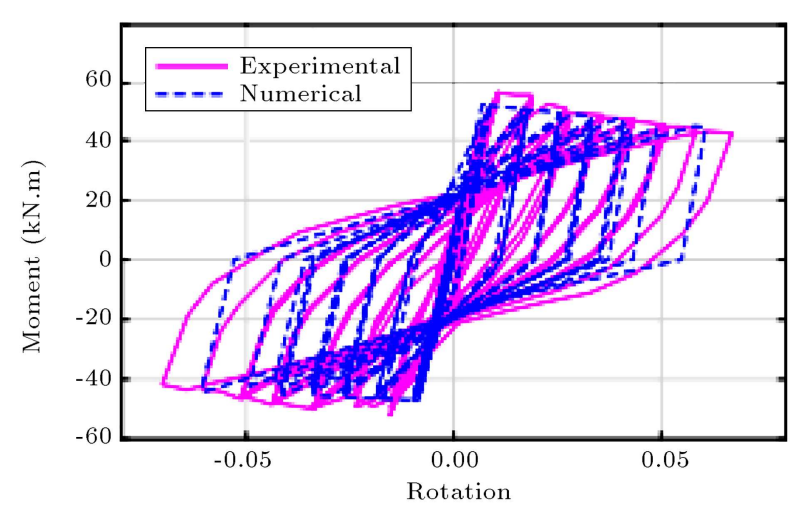

(b) Calibrated model

Figure 4. The model used for plastic hinge. 
Table 1. Effective stiffness of selective beam and column sections in a 9-story frame.

\begin{tabular}{|c|c|c|c|c|c|}
\hline \multicolumn{3}{|c|}{ Element properties } & \multicolumn{2}{|c|}{ ASCE } & \multirow{2}{*}{$\begin{array}{c}\text { Haselton } \\
K_{e} / K_{g}\end{array}$} \\
\hline Section & $\mathbf{R e}$ & iforcement & $P /\left(A_{g} f_{c}^{\prime}\right)$ & $\boldsymbol{K}_{e} / \boldsymbol{K}_{g}$ & \\
\hline \multirow{2}{*}{ B $40 \times 50$} & Top & $4 \varphi 22+4 \varphi 18$ & \multirow{2}{*}{0} & \multirow{2}{*}{0.3} & \multirow{2}{*}{0.28} \\
\hline & Bot & $4 \varphi 18$ & & & \\
\hline \multirow{2}{*}{ B $40 \times 45$} & Top & $4 \varphi 20+4 \varphi 18$ & \multirow{2}{*}{0} & \multirow{2}{*}{0.3} & \multirow{2}{*}{0.28} \\
\hline & Bot & $4 \varphi 18$ & & & \\
\hline C $50 \times 50$ & & $16 \varphi 25$ & 0.198 & 0.398 & 0.271 \\
\hline C $45 \times 45$ & & $12 \varphi 25$ & 0.163 & 0.363 & 0.275 \\
\hline C $40 \times 40$ & & $12 \varphi 25$ & 0.138 & 0.338 & 0.291 \\
\hline
\end{tabular}

In this paper, the above-mentioned parameters are used to model the beam-column dynamic behavior. For comparison purposes, two types of stiffness models are used. One is based on the model used by Haselton et al. [42] and the other one follows the recommendations in the ASCE/SEI 7 [8] regulation. The initial secant stiffness is in the following form based on ASCE/SEI 7 [8]:

$$
\left(\frac{E I_{y}}{E I_{g}}\right)_{A S C E}=0.2+\left[\frac{P}{A_{g} f_{c}^{\prime}}\right] \geq 0.3 .
$$

The values given to the parameter of the ratio of effective stiffness, $K_{e}$, of the un-coupled plastic hinge to stiffness of the un-cracked section, $K_{g}$, according to Haselton et al. [42] and ASCE/SEI 7 [8] for some beams and columns of a 9 -story building are given in Table 1. As seen, the stiffness of the columns based on the relationship provided by ASCE/SEI 7 [8], which depends on the axial load of the column, is greater than the average results of Haselton et al. [42].

\section{Nonlinear static analysis}

A group of static nonlinear analyses are performed on the built-in model in order to determine the relationship between the base shear and roof drift. This helps to quantify the sensitivity of different modeling parameters. Two lateral loading patterns are used for static nonlinear analyses of the 3-story frame, namely triangular and uniform. For other frames, the loading patterns include uniform distribution and spectral analysis-based shear distribution. The resulting curves in the form of base shear versus roof drift, also known as pushover or capacity curves, are shown in Figure 5.

In general, the capacity curves achieved by different modeling techniques are similar. The initial stiffness of the curves corresponding to the modeling with parameters recommended in ASCE/SEI 7 [8] is slightly higher than that in Haselton et al. [42]. Using these plots, the drift corresponding to the instability is determined. Based on FEMA P695 [44], it is equal to the drift at $80 \%$ of the maximum base shear
Table 2. Instability roof drift of the frames based on [42].

\begin{tabular}{ccc}
$\begin{array}{c}\text { Number of } \\
\text { stories }\end{array}$ & $\begin{array}{c}\text { Load } \\
\text { pattern }\end{array}$ & $\begin{array}{c}\text { Instability } \\
\text { drift }\end{array}$ \\
\hline 3 & Triangular & 0.073 \\
6 & Spectral & 0.062 \\
9 & Spectral & 0.059 \\
12 & Spectral & 0.052 \\
15 & Spectral & 0.049 \\
\hline
\end{tabular}

(i.e., the point at which resistance drops by 20\%). Table 2 illustrates drift values for the initiation of instability with the proposed parameters in Haselton et al. [42]. The results show that by increasing the stories, instability drift decreases. It can mainly be attributed to the geometric effects of the vertical loads.

\section{Incremental Dynamic Analysis (IDA)}

In general, there are many narrow- and wide-range analysis techniques that can be used for performance evaluation of structural and infra-structural systems $[45,46]$. In this paper, seismic performance of the frames is evaluated based on IDA $[47,48]$. This technique needs a group of ground motion records (usually from 20 to 40). According to Shome's recommendations [49], 20 ground motion records have been selected to investigate RTR variability in the demand parameters. Moment magnitude, $M_{w}$, varies from 6.5 to 7.5 and it has been selected based on seismic hazard analysis of Tehran province, Iran [50-53]. These ground motions are listed in Table 3 and the elastic response spectra are shown in Figure 6 .

In the IDA method, intensity of the selected ground motions increases gradually until the structure loses its dynamic stability (due to either collapse or numerical un-convergence). Therefore, 10 series of full IDA analyses are performed with five structural models and two types of stiffness assumptions. The associated single IDA curves along with the mean and standard deviations are shown in Figure 7 for effective stiffness based on the relationships in [42]. 


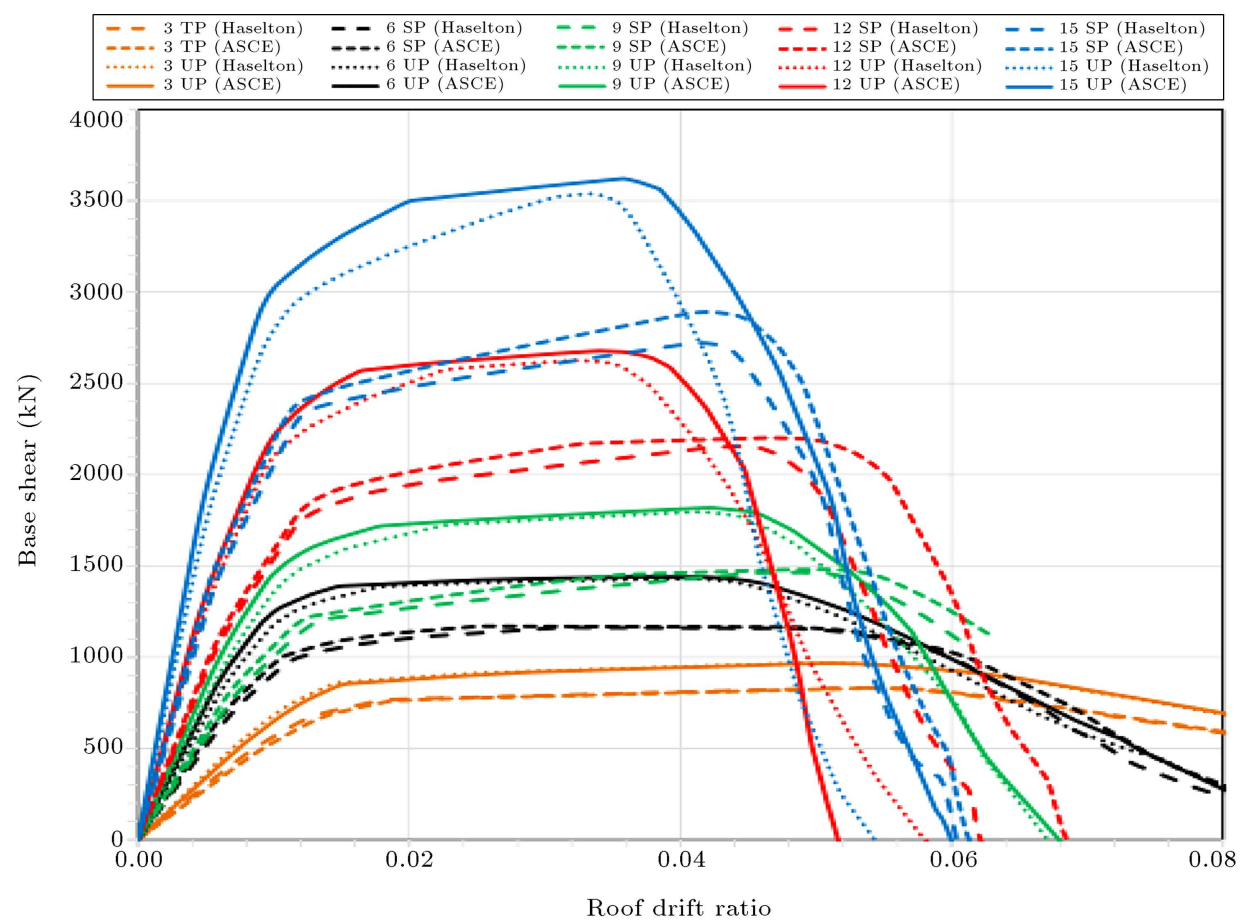

Figure 5. Base shear vs. roof drift ratio; SP: Spectral Pattern, UP: Uniform Pattern, and TP: Triangular Pattern.

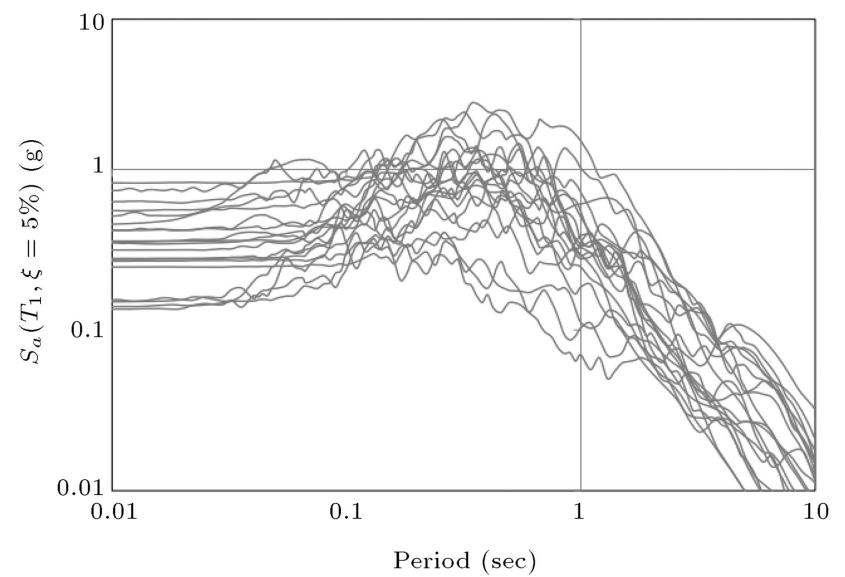

Figure 6. Acceleration response spectra for the selected ground motions.

Two LSs are considered, namely CP and GI. According to the IM-based rule [20], the last point (with the highest IM) on the IDA curve with a tangent slope $20 \%$ of that of the elastic part is defined as the $\mathrm{CP}$ point. This point should have the maximum interstory drift equal to or less than $10 \%$ of the maximum drift, i.e., $\theta_{\max }=10 \%$. If it exceeds this value, the point with $\theta_{\max }=10 \%$ is chosen as the $\mathrm{CP}$ point. Furthermore, the GI corresponds to the flat part of the IDA curve.

\section{Fragility curves and damage assessment}

A fragility function quantifies the probability of ex- ceeding a particular damage level (i.e., LS or structural collapse) as a function of ground motion IM [54]. The concept of fragility function in earthquake engineering goes back at least to the 1980s, when Kennedy et al. [55] defined a fragility function as a probabilistic relationship between frequency of failure (in their work, a component of nuclear power plant) and environmental excitation (they exclusively dealt with earthquakes and Peak Ground Acceleration (PGA)) [56].

The distinction among three fragility functions (namely empirical, analytical, and expert opinion) was discussed by Porter [57]. Empirical fragility curves are derived from post-earthquake damage data $[58,59]$. Analytical fragility curves are based on numerical transient structural analysis [60,61]. Finally, the heuristic fragility curves are developed based on expert opinion [62].

Usually, a log-normal Cumulative Distribution Function (CDF) is adopted to fit a fragility function [61]. The collapse fragility curve is quantified as:

$$
P[C \mid I M=i m]=\phi\left[\frac{\ln (i m)-\ln (\eta)}{\beta_{R T R}}\right],
$$

where $P[C \mid I M=i m]$ is the probability that the structure will collapse under a ground motion at the intensity level, $\mathrm{im}$; $C$ refers to structural collapse; $\phi($.$) is the standard normal CDF; \beta_{R T R}$ represents the logarithmic standard deviation (also called dispersion) due to RTR variability; and $\eta$ stands for the median of the fragility function [56]. 
Table 3. Detailed ground motion characteristics for Incremental Dunamic Analysis (IDA).

\begin{tabular}{|c|c|c|c|c|c|c|c|}
\hline ID & $M_{w}$ & Event & Fault & $\boldsymbol{R}_{\text {rup }}$ & Component & PGA (g) & $P G V(\mathrm{~cm} / \mathrm{s})$ \\
\hline 1 & 6.5 & Imperial Valley & Strike-slip & 12.6 & H-E11140 & 0.364 & 34.5 \\
\hline 2 & 6.5 & Imperial Valley & Strike-slip & 12.6 & H-E11230 & 0.38 & 42.1 \\
\hline 3 & 7.5 & Kocaeli, Turkey & Strike-slip & 17 & ARC090 & 0.149 & 39.5 \\
\hline 4 & 7.3 & Landers & Strike-slip & 21.2 & CLW-TR & 0.417 & 42.3 \\
\hline 5 & 6.9 & Loma Prieta & Strike-slip & 14.5 & CAP090 & 0.443 & 29.3 \\
\hline 6 & 6.9 & Kobe, Japan & Strike-slip & 0.6 & KJM000 & 0.821 & 81.3 \\
\hline 7 & 6.9 & Loma Prieta & Strike-slip & 25.8 & HDA 255 & 0.279 & 35.6 \\
\hline 8 & 7 & Cape Mendocino & Thrust & 18.5 & RIO360 & 0.549 & 42.1 \\
\hline 9 & 6.9 & Loma Prieta & Strike-slip & 25.8 & HDA165 & 0.269 & 43.9 \\
\hline 10 & 6.9 & Loma Prieta & Strike-slip & 28.2 & НCH090 & 0.247 & 38.5 \\
\hline 11 & 6.9 & Kobe, Japan & Strike-slip & 26.4 & KAK090 & 0.345 & 27.6 \\
\hline 12 & 6.5 & Imperial Valley & Strike-slip & 10.6 & $\mathrm{H}-\mathrm{CXO} 225$ & 0.275 & 21.2 \\
\hline 13 & 6.5 & Friuli, Italy & Thrust & - & A-TMZ270 & 0.315 & 30.8 \\
\hline 14 & 6.7 & Northridge & Blind thrust & 20.8 & MU2035 & 0.617 & 40.8 \\
\hline 15 & 7.1 & Duzce Turkey & Strike-slip & 17.6 & BOL000 & 0.728 & 56.4 \\
\hline 16 & 7.3 & Landers & Strike-slip & 24.9 & YER360 & 0.152 & 29.7 \\
\hline 17 & 6.7 & Northridge & Blind thrust & 19.6 & MUL009 & 0.416 & 59 \\
\hline 18 & 7.5 & Kocaeli, Turkey & Strike-slip & 12.7 & DZC270 & 0.358 & 46.4 \\
\hline 19 & 6.5 & Imperial Valley & Strike-slip & 11.1 & H-SHP270 & 0.506 & 30.9 \\
\hline 20 & 6.5 & Friuli, Italy & Thrust & - & A-TMZ000 & 0.351 & 22 \\
\hline
\end{tabular}

Based on the above discussion, the fragility curves are derived for the CP and GI LSs, as shown in Figure 8. The spectral acceleration at the first mode of the structure is taken as the IM parameter. It can be found that, in most cases, the fragility curves obtained through stiffness modeling with the experimental parameters [42] have higher probability than those obtained in [8]. The other major observation is that probability of exceedance for CP LS is higher than GI.

In order to investigate the impact of structural height on the probability of exceedance, the fragility curves for all the frames with the proposed modeling parameters in [42] are shown in Figure 9. It can be seen that increasing the height of the structure reduces the required IM parameters to meet a particular probability of exceedance. The reason can be attributed to the fact that increasing the structural height increases the fundamental vibration period. Subsequently, the spectral acceleration of the selected records decreases at the fundamental vibration period. This rule is feasible for the frames with 3 to 12 stories and the fragility curve of 15-story frame is lower than that of the 12-story one. In this case, increasing the fundamental vibration period leads to increase in the spectral acceleration as well. Thus, the frequency content of the selected ground motion records plays an important role in the performance assessment procedure.
In general, four types of uncertainties are considered in this paper:

- Ground motion RTR variability, $\beta_{R T R}$, which is directly obtained from the IDA curves;

- Modeling uncertainty, $\beta_{M D L}$, assumed to be 0.2 considering the fact that a comprehensive model of the frames has been developed [63];

- Uncertainty in designing requirements, $\beta_{D R}$, assumed to be 0.1 , because the studied buildings were designed according to the code requirements;

- Uncertainty in experimental test data, $\beta_{T D}$, assumed to be 0.2 , given the fact that many experimental tests were carried out to extract the forcedisplacement relation.

Finally, total uncertainty can be calculated using the Square Root of the Sum of the Squares (SRSS) rule [64]:

$$
\beta_{T O T}=\sqrt{\beta_{R T R}^{2}+\beta_{M D L}^{2}+\beta_{T D}^{2}+\beta_{D R}^{2}}
$$

Note that there are two major assumptions in Eq. (3):

1. All the uncertainty sources are independent;

2. The median of the fragility curve remains constant while the dispersion is altered. 


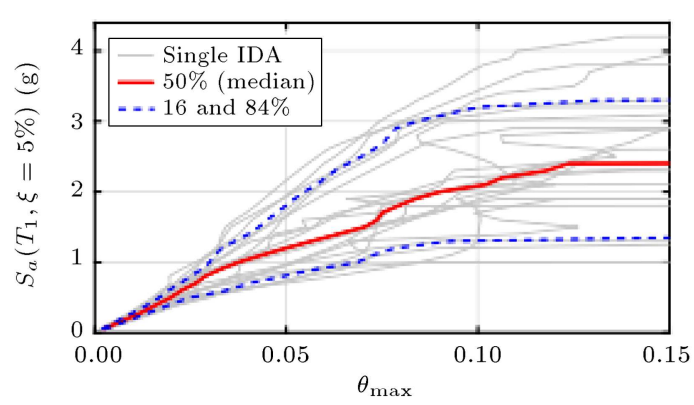

(a) 3 story

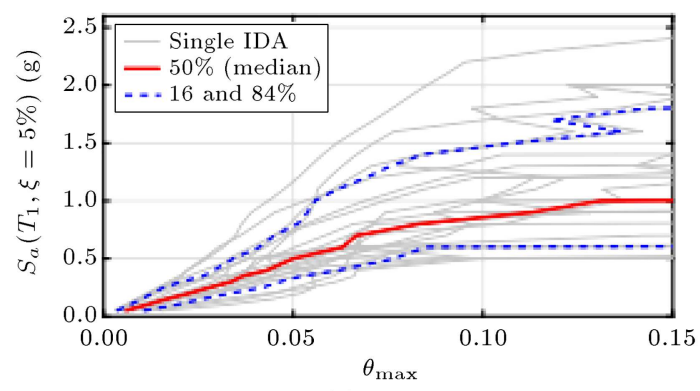

(c) 9 story

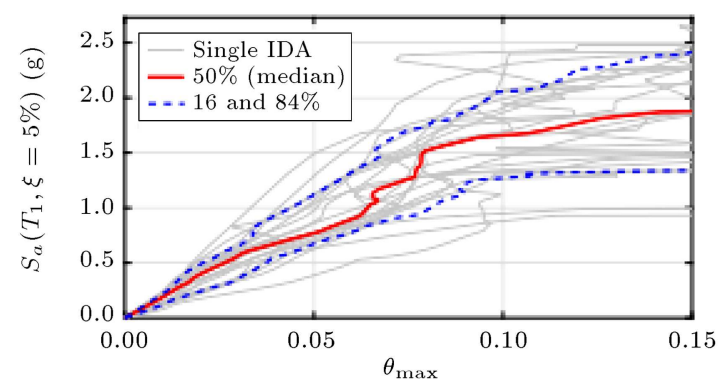

(b) 6 story

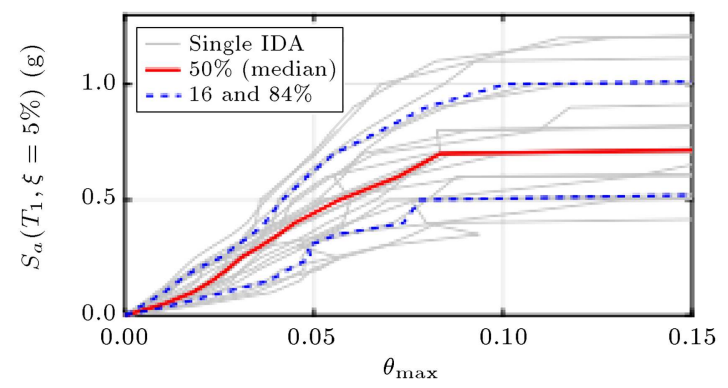

(d) 12 story

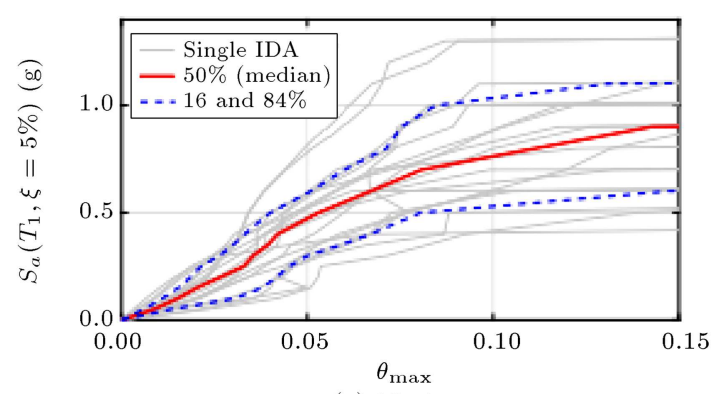

(e) 15 story

Figure 7. Incremental Dynamic Analysis (IDA) curves using the parameters proposed in [42].

Some of the recent studies have shown that the mate$\mathrm{rial} /$ modeling uncertainty not only increases dispersion but also affects the median response $[9,65]$ to some extent. However, for all the practical purposes, one can combine the uncertainties using Eq. (3) [66,67]. Figure 10 compares the collapse fragility curves for the 9-story frame using $\beta_{R T R}$ and $\beta_{T O T}$.

Results of this study can be used to evaluate the structural damage when the frames are subjected to the maximum credible earthquakes. The spectral accelerations for all the buildings are extracted from the seismic hazard maps of Tehran with a return period of 2,475 years (Figure 11) [68]. Two different locations are used with different seismicity conditions. Both are located on soil Type II, but with PGAs equal to 0.35 and $0.45 \mathrm{~g}$.

Using the developed fragility curves, the probability of exceedance of CP and GI LSs is determined (Figure 12). It can be seen that the potential instability of 3- and 6-story frames is lower than that of the other ones. The 9-story frame has the worst condition. Two major observations are:
1. Increasing the PGA level considerably increases the probability of exceedance of LSs;

2. At both PGA levels, the probability of exceedance of CP LS is higher than that of GI.

Moreover, one should notice the differences between two types of assumptions in modeling frame stiffness. For some of the frames subjected to a particular seismic hazard, using alternative stiffness modeling may help to decrease the probability of exceedance by up to a half.

\section{Reliability analysis}

Several factors generally contribute to the performance assessment and risk analysis of engineering structures. Probabilistic approaches are used to determine the earthquake ground motions and material uncertainties. Therefore, a statistical framework is required to compare the reliability of seismic responses.

In this paper, the confidence factor approach is used to estimate the collapse confidence levels. The 


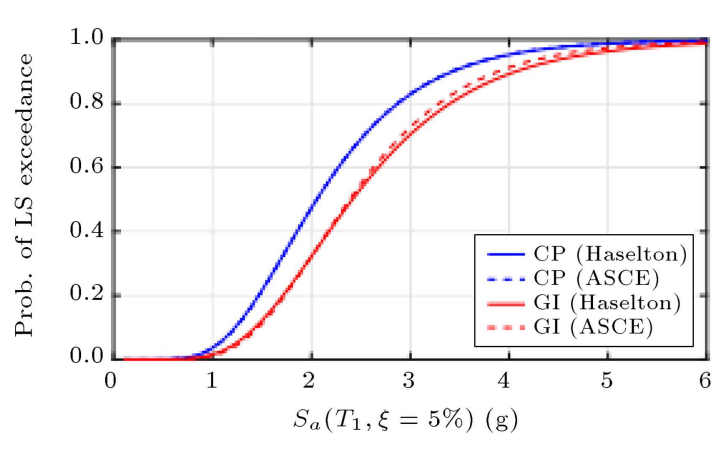

(a) 3 story

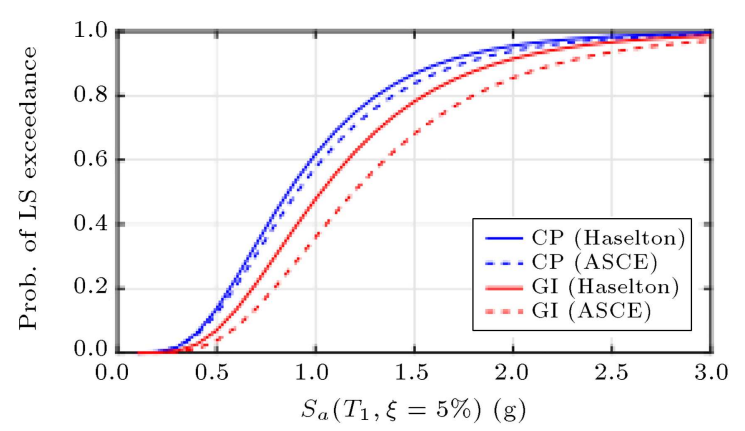

(c) 9 story

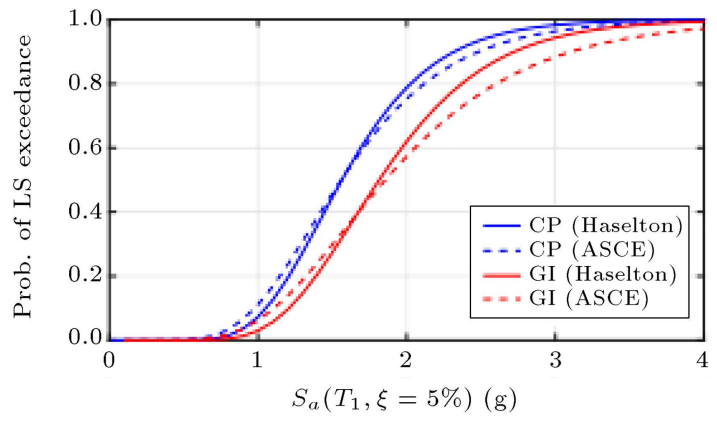

(b) 6 story

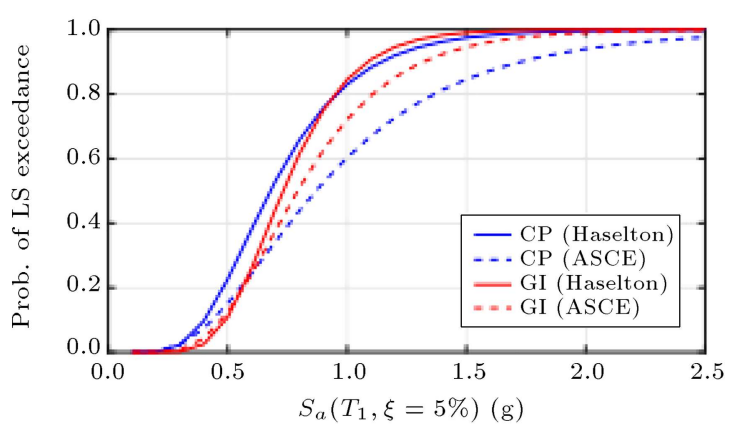

(d) 12 story

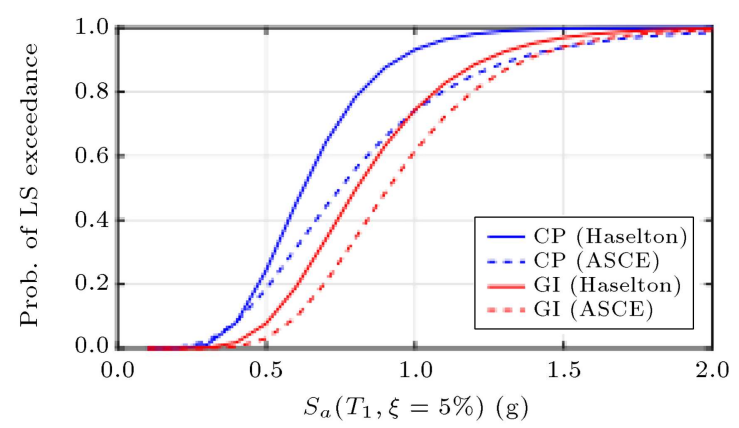

(e) 15 story

Figure 8. Fragility curves based on two stiffness model assumptions.

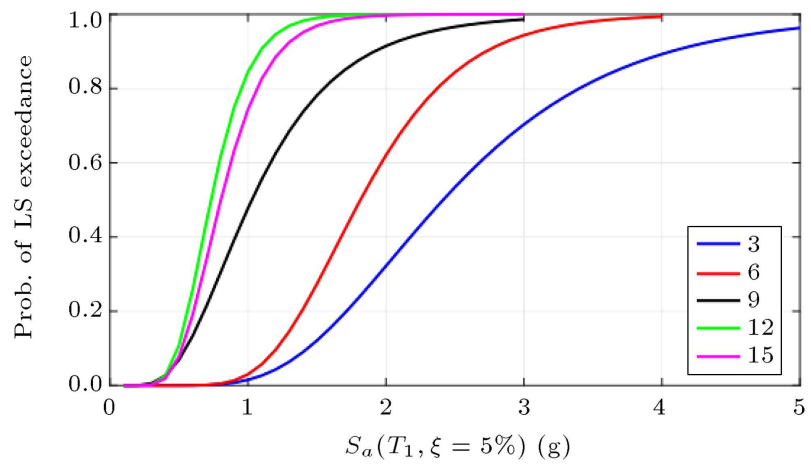

Figure 9. Impact of structural height on fragility curves.

fundamental concept of this approach can be found in [69-71] as it has been adopted by different researchers for various steel and concrete structures [72,73]. The target threshold is normally set to $90 \%$ confidence level for the CP LS in an earthquake with a return period of 2,475 years. It is noteworthy that the relationship and

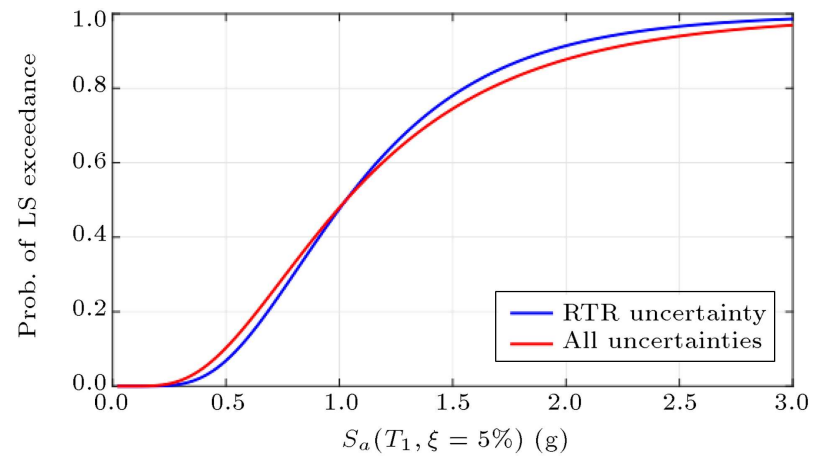

Figure 10. Impact of dispersion on fragility curves.

uncertainties used in this section are basically proposed for steel structures and, due to the lack of suitable data, similar values and relationships are used for concrete structures.

The acceptance criterion is based on a confidence factor, $\lambda$, which is used to determine the confidence 


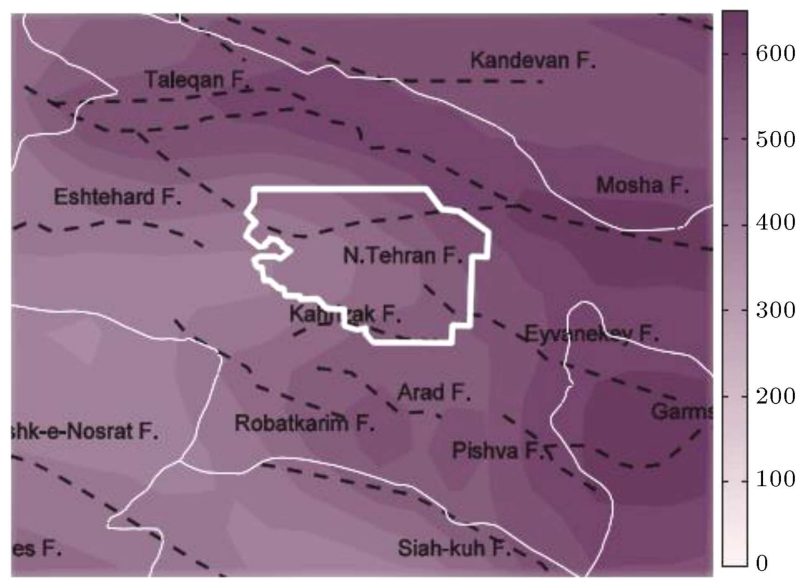

Figure 11. Hazard map of Tehran region; adopted from Zafarani et al. [68].

level. This factor is the ratio of factored demand to capacity and it can be expressed as:

$$
\lambda=\frac{\gamma \cdot \gamma_{a} \cdot D}{\varphi \cdot C}
$$

where $D$ presents the estimate of median drift demand, $C$ is the estimate of median drift capacity, $\varphi$ is resistance factor, $\gamma$ is demand factor, and $\gamma_{a}$ is analysis demand factor.

The resistance factor is computed as:

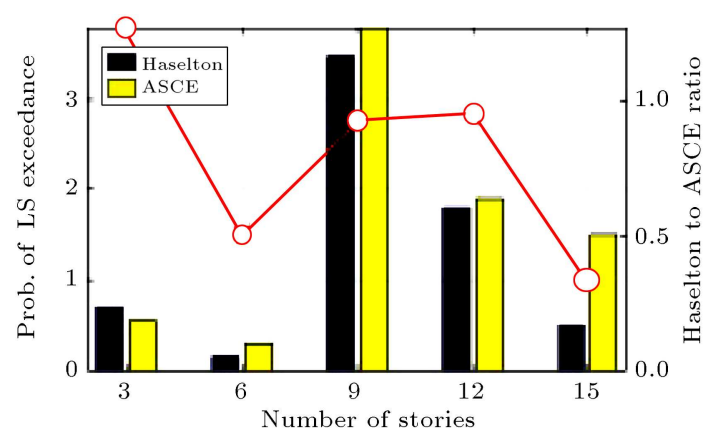

(a) $\mathrm{CP}, \mathrm{PGA}=0.35 \mathrm{~g}$

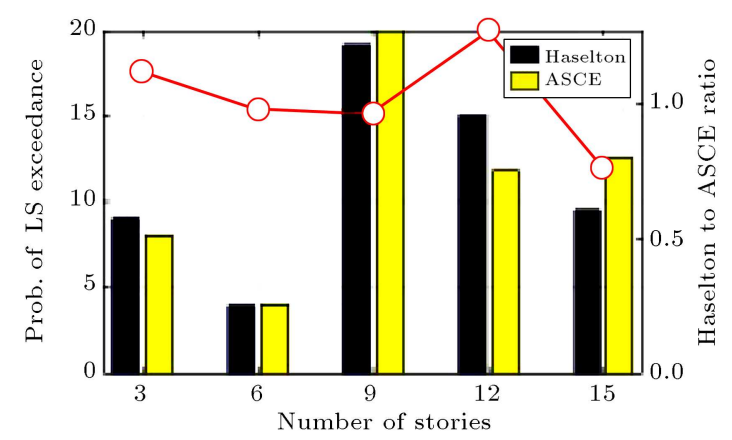

(c) $\mathrm{CP}, \mathrm{PGA}=0.45 \mathrm{~g}$

$$
\begin{aligned}
& \varphi=\varphi_{R C} \varphi_{U C}, \\
& \varphi_{R C}=e^{-k \beta_{R C}^{2} / 2 b}, \\
& \varphi_{U C}=e^{-k \beta_{U C}^{2} / 2 b},
\end{aligned}
$$

where $\varphi_{R C}$ is the contribution of ground motion variability to $\varphi ; \varphi_{U C}$ is the contribution of uncertainties in the measured component capacity to $\varphi ; \beta_{R C}$ can be interpreted at global level (i.e., standard deviation of the natural logs of the drift capacities from IDA analysis, independent from demand uncertainty) and local level (i.e., test variability in rotation capacity for the SAC project set to 0.20 based on test results); $\beta_{U C}$ is standard deviation of the natural logs of the drift capacities derived from experiment; $b$ is assumed to be 1.0 for this application; and $k$ represents the slope of the hazard curve calculated from Seismic hazard analysis.

The parameter $k$ is a function of the hazard level, location, and vibration period. The hazard curve is a plot of probability of exceedance of a spectral ordinate versus the spectral amplitude for a given period and is usually plotted on a logarithmic scale. In functional form, it is expressed as:

$$
H_{S i}\left(S_{i}\right)=k_{0} S_{i}^{-k} \text {. }
$$

The value of $k$ can be obtained by re-arranging the above equation with the two spectral values for any

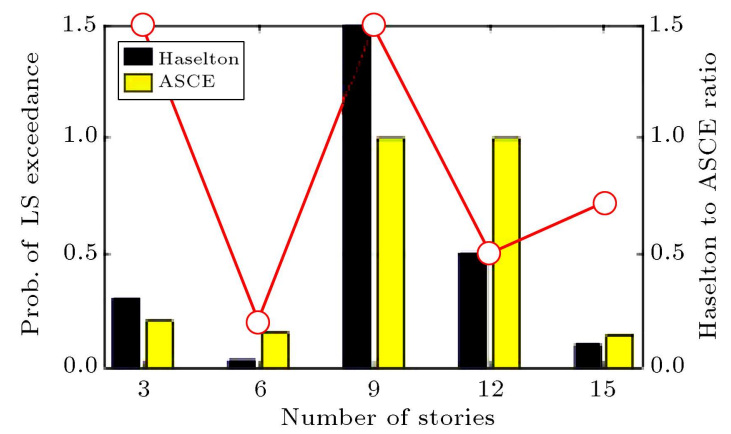

(b) GI, PGA $=0.35 \mathrm{~g}$

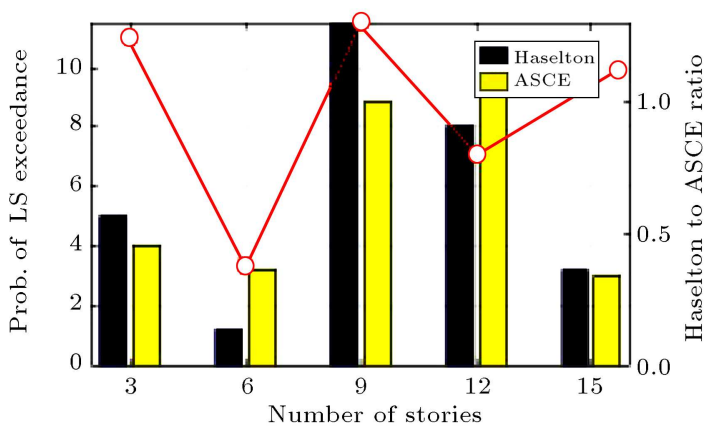

(d) GI, PGA $=0.45 \mathrm{~g}$

Figure 12. Probability of exceeding the Limit States (LSs) in an earthquake event with the return period of 2,475 years. 
two hazard levels. In this study, hazard levels of $2 \% / 50$ years and 10\%/50 years are used to calculate the slope of the curve, $k$. The equation is in the form:

$$
k=\frac{\ln \left[\frac{H_{S a}\left(S a_{10 \% / 50}\right)}{H_{S a}\left(S a_{2 \% / 50}\right)}\right]}{\ln \left[\frac{S a_{2 \% / 50}}{S a_{10 \% / 50}}\right]},
$$

where $S a_{2 \% / 50}$ and $S a_{10 \% / 50}$ are the spectral amplitudes for $2 \%$ and $10 \%$ in 50 years, respectively. Also, $H_{S a}\left(S a_{2 \% / 50}\right)$ and $H_{S a}\left(S a_{10 \% / 50}\right)$ represent the probabilities of exceedance for $2 \%$ and $10 \%$ in 50 years.

The capacities determined by testing are subject to uncertainties. In some cases, it is likely that there will not be enough specimens to calculate a reliable estimate of $\beta_{U C}$. In this case, it is recommended that the test data from similar specimens should be used along with the new test results. For SAC studies, $\beta_{U C}=0.25$ has been determined to be a good representative value. Since there is no established value for the concrete structures, we assume the same number as well.

The demand factor, $\gamma$, is calculated as:

$$
\gamma=e^{k \beta_{R D}^{2} / 2 b}, \quad \beta_{R D}=\sqrt{\sum \beta_{i}^{2}}
$$

where $\beta_{i}^{2}$ is the variance of the natural $\log$ of the drifts for each element of uncertainty.

The values of $\beta$ for each source of uncertainty and randomness are $\beta_{a c c}$ for ground motions (demand drifts) and $\beta_{\text {or }}$ for orientation. The orientation factor applies only to the near-fault California sites, where known faults are mapped. Hence, away from the near-fault sites, $\beta_{R D}=\beta_{a c c}$. For this case, $\beta_{a c c}$ is the standard deviation of the $\log$ of the maximum story drifts calculated for each of the 20 representative ground motions.

The demand factor $\gamma_{a}$ is based on the uncertainties related to the determination of demand, $D$, and calculated as:

$$
\gamma_{a}=e^{k \beta_{a}^{2} / 2 b}
$$

where $\beta_{a}$ is equal to the square root of the sum of the squares of the values of $\beta$ determined by each of the four uncertainty sources:

1. $\beta_{N T H}$ is associated with uncertainties in the nonlinear time history analysis procedure;

2. $\beta_{\text {damping }}$ is associated with uncertainty in estimating the damping value of the structure;

3. $\beta_{\text {live }}$ is associated with the uncertainty in the applied live load;

4. $\beta_{\text {material }}$ is associated with uncertainty in material property.
Only $\beta_{\mathrm{NTH}}$ and $\beta_{\text {damping }}$ are large enough to be included in RC moment-resisting buildings [74].

$\beta_{U T}$ is a function of all the uncertainty components. Therefore, it comprises uncertainties associated with the demand and capacity, but does not account for their stochastic nature. It only accounts for $\beta_{U}$ (from capacity) and $\beta_{a}$ (from demand). Therefore, $\beta_{U T}=\sqrt{\left(\beta_{C}^{2}+\beta_{a}^{2}\right)}$.

The confidence factor, $\lambda$, depends on the slope of the hazard curve, $k$, and the uncertainty associated with the natural $\log$ of the drifts:

$$
\lambda=e^{-\beta_{U T}\left(K_{x}-k \beta_{U T} / 2 b\right)},
$$

where $\beta_{U T}=\sum \beta_{i}^{2}\left(\beta_{i}\right.$ represents the uncertainties in demand and capacity) and $K_{x}$ is the standard Gaussian variate associated with probability $x$ of no exceedance. One can rewrite the equation as:

$$
K_{x}=\frac{1}{\beta_{U T}}\left[-\ln \lambda+\frac{k}{2 b} \beta_{U T}^{2}\right] .
$$

Finally, $K_{x}$ can be presented in a probabilistic form as:

$$
P\left(K_{x}\right)=\frac{1}{\sqrt{2 \pi}} \int_{-\infty}^{K_{x}} e^{-x^{2} / 2} d x .
$$

Using these equations, the confidence levels in CP and GI are calculated for all the buildings keeping in mind two locations with PGAs equal to 0.35 and $0.45 \mathrm{~g}$. Detailed calculations are reported in Tables 4 to 7 . It can be found that the frames with higher probabilities of collapse or instability have lower confidence levels. Also, it is observed that the collapse confidence level of the frames modeled with the proposed parameters in [42] is slightly lower than that of the models based on reference [8]. In case of the 12-story frame, the results are reverse. Tables 4 and 5 show that for the region with $P G A=0.35 \mathrm{~g}$, the confidence level for $\mathrm{CP}$ and GI is higher than $90 \%$. On the other hand, Tables 6 and 7 show that in the region with $P G A=0.45 \mathrm{~g}$, the confidence level for 9 - and 12-story frames is low enough to necessitate redesigning frames with higher resistance. In general, it is conventional to consider $90 \%$ confidence level as a threshold for the CP [66]. In the present study, we also accept the $90 \%$ confidence level for the GI LS in earthquake events with the return period of 2,475 years. Thus, in the regions with $P G A=0.35 \mathrm{~g}$, all the frames have an acceptable level of confidence against instability. However, in the area with $P G A=0.45 \mathrm{~g}$, the 9 - and-12 story frames should be redesigned.

\section{Summary}

The probabilities of dynamic instability were obtained via fragility curves. It was found that increasing 
Table 4. Collapse Prevention (CP) confidence level of frames under an earthquake event with the return period of 2,475 years and $P G A=0.35 \mathrm{~g}$.

\begin{tabular}{|c|c|c|c|c|c|c|c|c|c|c|c|}
\hline Stories & Modeling & $k$ & $C$ & $\varphi$ & $D$ & $\gamma$ & $\gamma_{a}$ & $\boldsymbol{\beta}_{U T}$ & $\lambda$ & $K_{x}$ & C.L. \\
\hline \multirow{2}{*}{3} & Haselton & 3.136 & 0.100 & 0.855 & 0.023 & 1.091 & 1.036 & 0.3 & 0.299 & 4.495 & 1 \\
\hline & ASCE & 3.136 & 0.100 & 0.85 & 0.025 & 1.100 & 1.036 & 0.3 & 0.327 & 4.192 & 1 \\
\hline \multirow{2}{*}{6} & Haselton & 3.136 & 0.100 & 0.84 & 0.02 & 1.195 & 1.049 & 0.35 & 0.283 & 4.151 & 1 \\
\hline & ASCE & 3.136 & 0.100 & 0.83 & 0.02 & 1.198 & 1.049 & 0.35 & 0.326 & 3.753 & 1 \\
\hline \multirow{2}{*}{9} & Haselton & 3.136 & 0.100 & 0.71 & 0.03 & 1.238 & 1.065 & 0.4 & 0.628 & 1.790 & 0.963 \\
\hline & ASCE & 3.136 & 0.100 & 0.76 & 0.03 & 1.304 & 1.065 & 0.45 & 0.574 & 2.014 & 0.978 \\
\hline \multirow{2}{*}{12} & Haselton & 3.136 & 0.100 & 0.66 & 0.03 & 1.187 & 1.074 & 0.43 & 0.554 & 2.054 & 0.980 \\
\hline & ASCE & 3.136 & 0.100 & 0.73 & 0.03 & 1.201 & 1.074 & 0.43 & 0.601 & 1.863 & 0.969 \\
\hline \multirow{2}{*}{15} & Haselton & 3.136 & 0.100 & 0.63 & 0.03 & 1.227 & 1.084 & 0.45 & 0.561 & 1.983 & 0.976 \\
\hline & ASCE & 3.136 & 0.100 & 0.66 & 0.03 & 1.230 & 1.084 & 0.45 & 0.643 & 1.685 & 0.955 \\
\hline
\end{tabular}

Table 5. Global Instability (GI) confidence level of frames under an earthquake event with the return period of 2,475 years and $P G A=0.35 \mathrm{~g}$.

\begin{tabular}{|c|c|c|c|c|c|c|c|c|c|c|c|}
\hline Stories & Modeling & $k$ & $C$ & $\varphi$ & $D$ & $\gamma$ & $\gamma_{a}$ & $\boldsymbol{\beta}_{U T}$ & $\lambda$ & $K_{x}$ & C.L. \\
\hline \multirow{2}{*}{3} & Haselton & 3.136 & 0.123 & 0.823 & 0.023 & 1.091 & 1.036 & 0.3 & 0.252 & 5.066 & 1 \\
\hline & ASCE & 3.136 & 0.116 & 0.82 & 0.025 & 1.100 & 1.036 & 0.3 & 0.276 & 4.765 & 1 \\
\hline \multirow{2}{*}{6} & Haselton & 3.136 & 0.127 & 0.75 & 0.02 & 1.195 & 1.049 & 0.35 & 0.251 & 4.495 & 1 \\
\hline & $\mathrm{ASCE}$ & 3.136 & 0.114 & 0.78 & 0.02 & 1.198 & 1.049 & 0.35 & 0.306 & 3.929 & 1 \\
\hline \multirow{2}{*}{9} & Haselton & 3.136 & 0.106 & 0.71 & 0.03 & 1.238 & 1.065 & 0.4 & 0.585 & 1.966 & 0.976 \\
\hline & $\mathrm{ASCE}$ & 3.136 & 0.111 & 0.74 & 0.03 & 1.304 & 1.065 & 0.45 & 0.543 & 2.058 & 0.980 \\
\hline \multirow{2}{*}{12} & Haselton & 3.136 & 0.091 & 0.75 & 0.03 & 1.187 & 1.074 & 0.43 & 0.540 & 2.113 & 0.983 \\
\hline & $\mathrm{ASCE}$ & 3.136 & 0.082 & 0.74 & 0.03 & 1.201 & 1.074 & 0.43 & 0.723 & 1.429 & 0.924 \\
\hline \multirow{2}{*}{15} & Haselton & 3.136 & 0.100 & 0.71 & 0.03 & 1.227 & 1.084 & 0.45 & 0.498 & 2.249 & 0.988 \\
\hline & ASCE & 3.136 & 0.110 & 0.71 & 0.03 & 1.230 & 1.084 & 0.45 & 0.543 & 2.058 & 0.980 \\
\hline
\end{tabular}

Table 6. Collapse Prevention (CP) confidence level of frames under an earthquake event with the return period of 2,475 years and $P G A=0.45 \mathrm{~g}$.

\begin{tabular}{|c|c|c|c|c|c|c|c|c|c|c|c|}
\hline Stories & Modeling & $k$ & $C$ & $\varphi$ & $D$ & $\gamma$ & $\gamma_{a}$ & $\boldsymbol{\beta}_{U T}$ & $\lambda$ & $K_{x}$ & C.L. \\
\hline \multirow{2}{*}{3} & Haselton & 1.927 & 0.100 & 0.91 & 0.041 & 1.781 & 1.022 & 0.3 & 0.811 & 0.986 & 0.839 \\
\hline & ASCE & 1.927 & 0.100 & 0.91 & 0.041 & 1.472 & 1.022 & 0.3 & 0.677 & 1.590 & 0.944 \\
\hline \multirow{2}{*}{6} & Haselton & 1.927 & 0.100 & 0.90 & 0.040 & 1.088 & 1.030 & 0.35 & 0.502 & 2.308 & 0.990 \\
\hline & ASCE & 1.927 & 0.100 & 0.89 & 0.041 & 1.299 & 1.030 & 0.35 & 0.617 & 1.718 & 0.957 \\
\hline \multirow{2}{*}{9} & Haselton & 1.927 & 0.100 & 0.81 & 0.052 & 1.491 & 1.039 & 0.4 & 1.007 & 0.367 & 0.644 \\
\hline & ASCE & 1.927 & 0.100 & 0.84 & 0.051 & 1.154 & 1.039 & 0.4 & 0.726 & 1.185 & 0.881 \\
\hline \multirow{2}{*}{12} & Haselton & 1.927 & 0.100 & 0.78 & 0.045 & 1.090 & 1.045 & 0.43 & 0.658 & 1.392 & 0.918 \\
\hline & ASCE & 1.927 & 0.100 & 0.82 & 0.051 & 1.129 & 1.045 & 0.43 & 0.727 & 1.158 & 0.877 \\
\hline \multirow{2}{*}{15} & Haselton & 1.927 & 0.100 & 0.75 & 0.039 & 1.093 & 1.051 & 0.45 & 0.600 & 1.563 & 0.941 \\
\hline & ASCE & 1.927 & 0.100 & 0.77 & 0.043 & 1.096 & 1.051 & 0.45 & 0.647 & 1.396 & 0.919 \\
\hline
\end{tabular}


Table 7. Global Instability (GI) confidence level of frames under an earthquake event with the return period of 2,475 years and $P G A=0.45 \mathrm{~g}$.

\begin{tabular}{|c|c|c|c|c|c|c|c|c|c|c|c|}
\hline Stories & Modeling & $k$ & $C$ & $\varphi$ & $D$ & $\gamma$ & $\gamma_{a}$ & $\boldsymbol{\beta}_{U T}$ & $\lambda$ & $K_{x}$ & C.L. \\
\hline \multirow{2}{*}{3} & Haselton & 1.927 & 0.123 & 0.89 & 0.041 & 1.781 & 1.022 & 0.3 & 0.674 & 1.606 & 0.946 \\
\hline & $\mathrm{ASCE}$ & 1.927 & 0.116 & 0.89 & 0.041 & 1.472 & 1.022 & 0.3 & 0.596 & 2.014 & 0.978 \\
\hline \multirow{2}{*}{6} & Haselton & 1.927 & 0.127 & 0.83 & 0.040 & 1.088 & 1.030 & 0.35 & 0.425 & 2.784 & 0.997 \\
\hline & $\mathrm{ASCE}$ & 1.927 & 0.114 & 0.86 & 0.041 & 1.299 & 1.030 & 0.35 & 0.565 & 1.968 & 0.976 \\
\hline \multirow{2}{*}{9} & Haselton & 1.927 & 0.106 & 0.81 & 0.052 & 1.491 & 1.039 & 0.4 & 0.943 & 0.533 & 0.702 \\
\hline & $\mathrm{ASCE}$ & 1.927 & 0.111 & 0.83 & 0.051 & 1.154 & 1.039 & 0.4 & 0.664 & 1.409 & 0.921 \\
\hline \multirow{2}{*}{12} & Haselton & 1.927 & 0.091 & 0.84 & 0.045 & 1.090 & 1.045 & 0.43 & 0.672 & 1.342 & 0.910 \\
\hline & ASCE & 1.927 & 0.082 & 0.83 & 0.051 & 1.129 & 1.045 & 0.43 & 0.878 & 0.716 & 0.764 \\
\hline \multirow{2}{*}{15} & Haselton & 1.927 & 0.100 & 0.81 & 0.039 & 1.093 & 1.051 & 0.45 & 0.557 & 1.726 & 0.948 \\
\hline & ASCE & 1.927 & 0.110 & 0.81 & 0.043 & 1.096 & 1.051 & 0.45 & 0.563 & 1.702 & 0.955 \\
\hline
\end{tabular}

structural height would increase the probability of Limit State (LS) exceedance and reduce the confidence level for Collapse Prevention (CP) and Global Instability (GI). This finding is especially significant with the high-rise frames, which are more vulnerable to earthquakes with higher return periods, indicating the incompetency of the existing building codes for designing high-rise structures. Hence, there is an urgent need for an update in these codes. Methods such as performance-based design might be a solution. Also, comparison of the probability of instability and collapse confidence level for different frames under different earthquake events showed that a higher relative hazard threshold than the existing one was required for the high-rise buildings.

Regarding the uncertainties in both structural modeling and record-to-record variability, probability of GI lay around $111.5 \%$ for earthquake ground motions with $2 \% / 50$ yrs. Similarly, the same scenario had a probability of $420 \%$ at CP performance level. The computed probabilities are high for the considered buildings. On the other hand, the target threshold for the confidence level was normally set to $90 \%$ for the LSs located in regions with a return period of 2,475 years. Therefore, the buildings with $P G A=0.35 \mathrm{~g}$ had an acceptable level of confidence against instability. However, the 9- and 12-story buildings with $P G A=$ $0.45 \mathrm{~g}$ should be re-designed.

\section{References}

1. Song, C., Pujol, S., and Lepage, A. "The collapse of the Alto Rio building during the 27 February 2010 maule, chile, earthquake", Earthquake Spectra, 28(S1), pp. 301-334 (2012).

2. Villaverde, R. "Methods to assess the seismic collapse capacity of building structures: State of the art", Journal of Structural Engineering, 133(1), pp. 57-66 (2007).

3. Kunnath, S.K., Reinhorn, A.M., and Park, Y.J. "Analytical modeling of inelastic seismic response of $\mathrm{r} / \mathrm{c}$ structures", Journal of Structural Engineering, 116(4), pp. 996-1017 (1990).

4. Baker, J.W. and Allin Cornell, C. "Spectral shape, epsilon and record selection", Earthquake Engineering \& Structural Dynamics, 35(9), pp. 1077-1095 (2006).

5. Mazzoni, S., McKenna, F., Scott, M.H., and Fenves, G.L., OpenSees Command Language Manual, Pacific Earthquake Engineering Research (PEER) Center, 264 (2006).

6. Goulet, C.A., Haselton, C.B., Mitrani-Reiser, J., Beck, J.L., Deierlein, G.G., Porter, K.A., and Stewart, J.P. "Evaluation of the seismic performance of a code-conforming reinforced concrete frame building from seismic hazard to collapse safety and economic losses", Earthquake Engineering \& Structural Dynamics, 36(13), pp. 1973-1997 (2007).

7. Haselton, C.B., Liel, A.B., Dean, B.S., Chou, J.H., and Deierlein, G.G. "Seismic collapse safety and behavior of modern reinforced concrete moment frame buildings", In Structural Engineering Research Frontiers, pp. 1-14 (2007).

8. ASCE/SEI 7 "Minimum design loads for buildings and other structures", Technical Report, American Society of Civil Engineers (2010).

9. Liel, A., Haselton, C., Deierlein, G., and Baker, J. "Incorporating modeling uncertainties in the assessment of seismic collapse risk of buildings", Structural Safety, 31, pp. 197-211 (2009).

10. Ibarra, L.F. and Krawinkler, H. "Global collapse of frame structures under seismic excitations", Technical Report, Pacific Earthquake Engineering Research Center Berkeley, CA (2005). 
11. Haselton, C., Liel, A., Deierlein, G., Dean, B., and Chou, J. "Seismic collapse safety of reinforced concrete buildings. I: Assessment of ductile moment frames", Journal of Structural Engineering, 137, pp. 481-491 (2011).

12. American Concrete Institute "Building code requirements for structural concrete (ACI 318-08) and commentary", Technical Report (2008).

13. Dolsek, M. "Incremental dynamic analysis with consideration of modeling uncertainties", Earthquake Engineering and Structural Dynamics, 38, pp. 805-825 (2009).

14. Celarec, D. and Dolsek, M. "The impact of modelling uncertainties on the seismic performance assessment of reinforced concrete frame buildings", Engineering Structures, 52, pp. 340-354 (2013).

15. Li, Y., Lu, X., Guan, H., and Ye, L. "An improved tie force method for progressive collapse resistance design of reinforced concrete frame structures", Engineering Structures, 33(10), pp. 2931-2942 (2011).

16. Kam, W.Y., Pampanin, S., and Elwood, K. "Seismic performance of reinforced concrete buildings in the 22 February Christchurch (Lyttelton) earthquake", Bulletin of the New Zealand Society for Earthquake Engineering 44.4, pp. 239-278 (2011).

17. Fragiadakis, M., Vamvatsikos, D., and Aschheim, M. "Application of nonlinear static procedures for the seismic assessment of regular RC moment frame buildings", Earthquake Spectra, 30(2), pp. 767-794 (2014).

18. Lu, X., Lu, X., Guan, H., and Ye, L. "Collapse simulation of reinforced concrete high-rise building induced by extreme earthquakes", Earthquake Engineering \& Structural Dynamics, 42(5), pp. 705-723 (2013).

19. Raghunandan, M. and Liel, A.B. "Effect of ground motion duration on earthquake-induced structural collapse", Structural Safety, 41, pp. 119-133 (2013).

20. Ibarra, L.F., Medina, R.A., and Krawinkler, H. "Hysteretic models that incorporate strength and stiffness deterioration", Earthquake Engineering \& Structural Dynamics, 34(12), pp. 1489-1511 (2005).

21. Raghunandan, M., Liel, A.B., and Luco, N. "Aftershock collapse vulnerability assessment of reinforced concrete frame structures", Earthquake Engineering \& Structural Dynamics, 44(3), pp. 419-439 (2015).

22. Riahi, H.T., Amouzegar, H., and Fosoul, S.A.S. "Comparative study of seismic structural response to real and spectrum matched ground motions", Scientia Iranica, Transaction A, Civil Engineering, 22(1), p. 92 (2015).

23. Sattar, S. and Liel, A.B. "Collapse indicators for existing nonductile concrete frame buildings with varying column and frame characteristics", Engineering Structures, 152, pp. 188-201 (2017).

24. Burton, H. and Deierlein, G. "Simulation of seismic collapse in nonductile reinforced concrete frame buildings with masonry infills", Journal of Structural Engineering, 140(8), A4014016 (2013).
25. Sattar, S. and Liel, A.B. "Seismic performance of nonductile reinforced concrete frames with masonry infill walls I: Development of a strut model enhanced by finite element models", Earthquake Spectra, 32(2), pp. 795-818 (2016).

26. Haghpanah, F., Foroughi, H., and Behrou, R. "Sustainable seismic retrofitting of a RC building using performance based design approach", Engineering Structures and Technologies, 9(3), pp. 133-141 (2017).

27. Tafakori, E., Pourzeynali, S., and Estekanchi, H. "Assessment of collapse modes in reinforced concrete frames considering record-to-record and modeling uncertainties", Scientia Iranica, Transaction A, Civil Engineering, 24(5), pp. 2213-2226 (2017).

28. Kueht, E. and Hueste, M.B. "Impact of code requirements in the central united states: Seismic performance assessment of a reinforced concrete building", Journal of Structural Engineering, 135(4), pp. 404413 (2009).

29. Kim, T. and Kim, J. "Seismic demand of a RC special moment frame building", The Structural Design of Tall and Special Buildings, 18(2), pp. 137-147 (2009).

30. Panagiotakos, T.B. and Fardis, M.N. "Seismic performance of $\mathrm{RC}$ frames designed to eurocode 8 or to the Greek codes 2000", Bulletin of Earthquake Engineering, 2(2), pp. 221-259 (2004).

31. Kotronis, P., Ragueneau, F., and Mazars, J. "A simplified modelling strategy for $\mathrm{r} / \mathrm{c}$ walls satisfying ps92 and ec8 design", Engineering Structures, 27(8), pp. 1197-1208 (2005).

32. Sadjadi, R., Kianoush, M., and Talebi, S. "Seismic performance of reinforced concrete moment resisting frames", Engineering Structures, 29(9), pp. 2365-2380 (2007).

33. Tena-Colunga, A., Correa-Arizmendi, H., LunaArroyo, J.L., and Gatica-Aviles, G. "Seismic behavior of code-designed medium rise special moment-resisting frame RC buildings in soft soils of Mexico city", Engineering Structures, 30(12), pp. 3681-3707 (2008).

34. Mehanny, S. and El Howary, H. "Assessment of RC moment frame buildings in moderate seismic zones: Evaluation of Egyptian seismic code implications and system configuration effects", Engineering Structures, 32(8), pp. 2394-2406 (2010).

35. El Howary, H. and Mehanny, S. "Seismic vulnerability evaluation of $\mathrm{RC}$ moment frame buildings in moderate seismic zones", Earthquake Engineering \& Structural Dynamics, 40(2), pp. 215-235 (2011).

36. Duan, H. and Hueste, M.B.D. "Seismic performance of a reinforced concrete frame building in china", Engineering Structures, 41, pp. 77-89 (2012).

37. Astriana, L., Sangadji, S., Purwanto, E., and Kristiawan, S. "Assessing seismic performance of moment resisting frame and frame-shear wall system using seismic fragility curve", Procedia Engineering, 171, pp. 1069-1076 (2017). 
38. Saloor, N. and Salari, A., Seismic Hazards in Iran (2015).

39. Behrou, R., Panah, A.K., and Ghayamghamian, M.R. "Recorded bedrock motions and site effects evaluation in Tehran city", In 7th International Conference on Case Histories in Geotechnical Engineering (2013).

40. Behrou, R., Haghpanah, F., and Foroughi, H. "Seismic site effect analysis for the city of Tehran using equivalent linear ground response analysis", International Journal of Geotechnical Engineering (2017). DOI: $10.1080 / 19386362.2017 .1395998$

41. Manual, ETABS User'S. Integrated Building Design Software, Computer and Structure Inc. Berkeley, USA (2002).

42. Haselton, C., Liel, A., Taylor Lange, S., and Deierlein, G., Beam-Column Element Model Calibrated for Predicting Flexural Response Leading to Global Collapse of $R C$ Frame Buildings, Pacific Earthquake Engineering Research Center (2007).

43. Khanmohammadi, M. "Displacement and damage index criteria in performance based seismic design of R.C buildings", PhD Thesis, Department of Civil Engineering, University of Tehran (in Persian), Tehran (2006).

44. FEMA "Quantification of building seismic performance factors", FEMA P695. Redwood City, CA: Applied Technology Council (2009).

45. Hariri-Ardebili, M., Zarringhalam, Y., Estekanchi, H., and Yahyai, M. "Non-linear seismic assessment of steel moment frames using time-history, incremental dynamic, and endurance time analysis methods", Scientia Iranica, 20(3), pp. 431-444 (2013).

46. Hariri-Ardebili, M.A., Sattar, S., and Estekanchi, H.E. "Performance-based seismic assessment of steel frames using endurance time analysis", Engineering Structures, 69, pp. 216-234 (2014).

47. Vamvatsikos, D. and Cornell, C. "Incremental dynamic analysis", Earthquake Engineering and Structural Dynamics, 31, pp. 491-514 (2002).

48. Vamvatsikos, D. and Cornell, C. "Applied incremental dynamic analysis", Earthquake Spectra, 20, pp. 523553 (2004).

49. Shome, N. "Probabilistic seismic demand analysis of nonlinear structures", PhD thesis, Stanford University, Stanford (1999).

50. McGuire, R. "Probabilistic seismic hazard analysis and design earthquakes: Closing the loop", Bulletin of the Seismological Society of America, 85, pp. 1275-1284 (1995).

51. Amiri, G.G., Motamed, R., and Es-Haghi, H.R. "Seismic hazard assessment of metropolitan Tehran, Iran", Journal of Earthquake Engineering, 7(3), pp. 347-372 (2003).

52. Jafari, M.A. "Statistical prediction of the next great earthquake around Tehran, Iran", Journal of Geodynamics, 49(1), pp. 14-18 (2010).
53. Hashemi, M., Alesheikh, A.A., and Zolfaghari, M.R. "A spatio-temporal model for probabilistic seismic hazard zonation of Tehran", Computers \& Geosciences, 58, pp. 8-18 (2013).

54. Baker, J. "Efficient analytical fragility function fitting using dynamic structural analysis", Earthquake Spectra, 31(1), pp. 579-599 (2015).

55. Kennedy, R., Cornell, C., Campbell, R., Kaplan, S., and Perla, H. "Probabilistic seismic safety study of an existing nuclear power plant", Nuclear Engineering and Design, 59, pp. 315-338 (1980).

56. Hariri-Ardebili, M. and Saouma, V. "Collapse fragility curves for concrete dams: Comprehensive study", ASCE Journal of Structural Engineering, 142(10), 04016075 (2016).

57. Porter, K. "Assembly-based vulnerability of buildings and its uses in seismic performance evaluation and riskmanagement decision-making", PhD Thesis, Stanford University, Stanford, Palo-Alto, CA (2000).

58. Kustu, O., Miller, D., and Broken, S. "Development of damage functions for high-rise building", Technical Report, URS/John A. Blume and Associates, Engineers, San Francisco, CA (1982).

59. Sabetta, F., Goretti, A., and Lucantoni, A. "Empirical fragility curves from damage surveys and estimated strong ground motion", In Proceedings of the 11th European Conference on Earthquake Engineering, Paris, France (1998).

60. Czarnecki, R. "Earthquake damage to tall buildings, optimum seismic protection and building damage statistics", Report No. 5. PhD thesis, Massachusetts Institute of Technology, Department of Civil Engineering, Cambridge, MA (1973).

61. Shinozuka, M., Feng, M., Lee, J., and Naganuma, T. "Statistical analysis of fragility curves", Journal of Engineering Mechanics, 126, pp. 1224-1231 (2000).

62. Kennedy, R. and Ravindra, M. "Seismic fragilities for nuclear power plant risk studies", Nuclear Engineering and Design, 79(1), pp. 47-68. (1984).

63. Applied Technology Council "Seismic performance assessment of buildings volume 1 - methodology", Technical Report FEMA P-58-1, Federal Emergency Management Agency (2012a).

64. Cornell, A., Jalayer, F., and Hamburger, R. "Probabilistic basis for 2000 SAC federal emergency management agency steel moment frame guidelines", Journal of Structural Engineering, 128, pp. 526-532 (2002).

65. Dolsek, M. "Simplified method for seismic risk assessment of buildings with consideration of aleatory and epistemic uncertainty", Structure and Infrastructure Engineering, 8, pp. 939-953 (2012).

66. Vamvatsikos, D. and Fragiadakis, M. "Incremental dynamic analysis for estimating seismic performance sensitivity and uncertainty", Earthquake Engineering and Structural Dynamics, 39, pp. 141-163 (2010). 
67. Applied Technology Council "Seismic performance assessment of buildings, Volume 1: Methodology" Technical Report ATC-58-1, Federal Emergency Management Agency, Redwood City, CA (2012b).

68. Zafarani, H., Hajimohammadi, B., and Jalalalhosseini, S.M. "Earthquake hazard in the Tehran region based on the characteristic earthquake model", Journal of Earthquake Engineering, 23(9), pp. 1485-1511 (2019).

69. Wen, Y. and Foutch, D.A. "Proposed statistical and reliability framework for comparing and evaluating predictive models for evaluation and design", SAC/BD 97/03.

70. Hamburger, R. "A framework for performance-based earthquake resistive design", NISEE: National Information Service for Earthquake Engineering (1997).

71. Jalayer, F. "Direct probabilistic seismic analysis: implementing non-linear dynamic assessments", $\mathrm{PhD}$ Thesis, Stanford University, Stanford, Palo-Alto, CA (2003).

72. Foutch, D.A. and Wilcoski, J.A. "Rational approach for determining response modification factors for seismic design of buildings using current code provisions", Earthquake Spectra., 21(2), pp. 339-352 (2005).

73. Kim, T., Foutch, D.A., Wilcoski, J., and LaFave, J.M. "Response modification factors for RC case-study buildings with structural walls", Earthquake Spectra., 25(4), pp. 803-819 (2009).

74. Foutch, D.A. "State of the art report on performance prediction and evaluation of steel momentframe buildings", SAC Rep. No. FEMA 355f, Federal Emergency Management Agency, Washington, DC (2000).

\section{Biographies}

Seyed Abbas Hoseini received his BSc in Civil Engineering and MSc in Earthquake Engineering. Currently, he is a $\mathrm{PhD}$ candidate at Sharif University of Technology. He is also an Assistant Professor at Islamic Azad University, Germi Branch, Iran. His research interests are finite element modeling of building frames, dynamic analysis, and seismic performance assessment of structures.

Mohsen Ghaemian is a Professor in Civil Engineering Department of Sharif University of Technology. His current academic activities are focused on concrete technology, dynamic responses of gravity, and arch dams. Dam reservoir interaction effects, seismic response of dams due to non-uniform excitations, and nonlinear behavior of concrete dams have been his research interests in recent years.

Mohammad Amin Hariri-Ardebili, $\mathrm{PhD}$, is a research associate and adjunct faculty member in the Department of Structural Engineering and Mechanics at University of Colorado, Boulder (USA). His main research interests are performance-based assessment of major structures (dams, towers, and nuclear containment vessels), coupled systems mechanics, mathematical models, and machine learning in structural engineering. He is currently an Associate Editor for Frontiers in Built Environment and editor for Mathematical Problems in Engineering. 